\title{
The Prevalence of HPV Genotypes in Iranian Population: An Update
}

\author{
Mina Mobini Kesheh ${ }^{1}$ (D), Hossein Keyvani ${ }^{*}$ (iD
}

1. Student Research Committee, Department of Virology, School of Medicine, Iran University of Medical Science, Tehran, Iran

2. Department of Virology, School of Medicine, Iran University of Medical Science, Tehran, Iran

\section{KEYWORDS \\ Human papillomavirus (HPV), \\ Age distribution, \\ Genotype distribution, Iran, \\ INNO-LiPA HPV genotyping \\ Scan to discover online

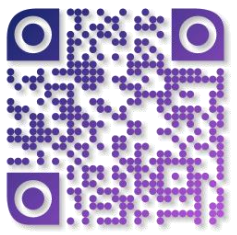

\begin{tabular}{c}
\hline $\begin{array}{c}\text { Main Subjects: } \\
\text { Microbiology }\end{array}$ \\
\hline Received 22 Nov 2018; \\
Accepted 12 Jul 2019; \\
Published Online 01 Aug 2019; \\
\hline
\end{tabular}

10.30699/ijp.2019.90356.1861

PMCID:

PMID:

\section{ABSTRACT}

Background \& Objective: Human papillomavirus (HPV) is the main cause of genital warts and some anogenital cancers in male and female subjects which is commonly transmitted by sexual contacts. The objective of this cross-sectional study was to examine the prevalence of HPV genotypes in 10,266 Iranian male and female population, according to their age.

Methods: Samples were collected from the penile and anal sites of male subjects and the vagina and cervix of female subjects in a time period between 2011 and 2016. HPV DNA was detected in PCR using the MY09 and MY11 primers, and the INNO-LiPA assay was applied for HPV genotyping. To investigate the relevance of HPV infection and age, the samples were classified into 4 age groups (13-29, 30-44, 45-59, and 60-74).

Results: Totally, the most common low risk HPV genotypes detected in the studied male and female subjects were HPV-6 (77.7\% and 43.3\%) and HPV-11 (13.7\% and $11.4 \%)$, and more frequent high risk HPV genotypes were HPV-16 (5.5\% and $16.6 \%)$ and HPV-52 (3.2\% and 9.6\%), respectively. High burden of the HPV infection was observed at ranges of 30 and 44 years $(51.8 \%)$ with a peak at ranges between 30 and 32 years. No considerable statistically significant correlation was found between HPV infection and age $(P=1)$.

Conclusion: This study gave an epidemiological overview of circulating HPV genotypes in Iranian population to develop future vaccination policies, though the findings of prevalent HPV genotypes in female subjects were inconsistent with the previous studies reported in Iran.

\section{Corresponding Information:}

Hossein Keyvani, Department of Virology, School of Medicine, Iran University of Medical Science, Tehran, Iran Email: maaflatoonian@gmail.com

Copyright ( $\odot$ 2019. This is an open-access article distributed under the terms of the Creative Commons Attribution- 4.0 International License which permits

Share, copy and redistribution of the material in any medium or format or adapt, remix, transform, and build upon the material for any purpose, even commercially.

\section{Introduction}

More than 210 Human papillomavirus (HPV) genotypes have been detected so far. Adequate documents show that there is a relationship between HPV and some human cancers such as cervix cancer, head and neck carcinoma, penile cancer, oropharyngeal squamous cell carcinomas and, anal cancers $(1,2)$. According to the most recent meta-analysis study conducted on Iranian healthy female and female subjects with cervical cancer, the prevalence of HPV infection was $9.4 \%$ and $77.4 \%$, respectively. The predominant genotype in both groups was HPV-16 $(3,4)$. Based on an estimated worldwide study published by the international agency for research on cancer (IARC), the HPV prevalence in female subjects with normal cytology in Africa, Latin America, Northern America, Asia, and Europe was 22.9\%, 18.6\%, 13.8\%, 8.3\%, and $6.6 \%$, respectively and in a descending order (5). In less developed countries, cervix cancer is the second most common cancer (5) caused mostly by HPV-16 and -18 (6); however, cervical cancer is the $12^{\text {th }}$ most common cancer among Iranian female subjects (7). In male subjects, HPV-16 is the most frequent HPV genotype detected in penile cancer, and HPV- 6 and -11 are often seen in genital warts (8). Although few studies have been carried out on HPV genotype distribution in Iranian male subjects, a recent study reported the $55.7 \%$ prevalence of HPV with HPV-6 as the most frequent genotype (9). HPV is an important agent in sexually transmitted diseases; screening and HPV genotyping tests, especially in low and middle income countries where HPV vaccination programs are not established, may help to improve the public health and prevent the spread of HPV infection (10). Even though Gardasil 4-valent is available in Iran, no national program exists to administer the vaccine to girls and boys.

The main objective of this study was to evaluate the distribution of HPV genotypes among Iranian males and females and provide a perspective of the dominant genotypes in the country. Although different studies on female or male samples have been accomplished in 
various provinces of Iran, as far the researchers investigated, this study is the first survey in Iran with a large sample size and participation of both male and female subjects. The findings might be helpful not only for setting future investigations and an agenda for public health, but also for vaccine development and national vaccination planning.

\section{Materials and Methods}

\section{Procedure}

In this cross-sectional study, a total of $8,351(81.3 \%)$ females and 1,915 (18.7\%) males from different provinces of Iran who were referred to Keyvan Laboratory of Tehran for HPV DNA testing and genotyping between April 2011 and April 2016 were enrolled. Almost all subjects were sexually active with an age range from 13 to 74 years old. The HPV DNA testing and genotyping were ordered by clinicians. Male samples were collected from anal and penile biopsies and female samples from the vagina and cervix through the use of either Dacron swabs or brush.

For DNA extraction, QIAamp DNA Mini kit (Qiagen $\mathrm{GmbH}$, Germany) was utilized in accordance with the manufacturer's directions and the concentration of extracted DNA was evaluated by spectrophotometry in $260 \mathrm{~nm}$. Genomic DNA of the samples was used in PCR using the MY09 and MY11 primers. DNA quality in samples was verified using beta-globin PCR assay.

Detection of HPV DNA and genotypes were carried out using INNO-LiPA assay (Fujirebio Europe N. V., Belgium). The INNO-LiPA HPV genotyping is based on the principle of reverse hybridization. Briefly, a part of L1 region called SPF10 of HPV genome was extended by specific primers; then, the biotinylated amplimers were denatured and hybridized with specific oligonucleotide probes. Furthermore, a primer pair of the human HLA-DPB1 gene was added to confirm the quality and extraction of DNA. Next, streptavidinconjugated alkaline phosphatase was added. After incubation with BCIP/NBT chromogen, the results were interpreted visually.

\section{Statistical analysis}

IBM SPSS statistics version 22 (11) was used for statistical analysis as follows: 95\% CI for prevalence estimations and the relation of HPV infection with age was performed using the Kruskal-Wallis test. A P-value less than 0.05 was considered to be statistically significant.

\section{Results}

INNO LiPA HPV genotyping determined $32 \mathrm{HPV}$ genotypes; HPV-16, -18, -31, -33, -35, -39, -45, -51, $52,-56,-58,-59$, and -68 as high risk HPV genotypes (HR HPV), HPV-26, -53, -66, -70, -73, and -82 as possible high risk HPV genotypes (pHR HPV), and HPV-6, -11, -40, -42, -43, -44, -54, -61, -62, -67, -81, 83 , and -89 as low risk HPV genotypes (LR HPV). This HPV classification was based on IARC Monographs (12). During the study period, the total HPV prevalence was 49.5\%; hence, among 10,266 participants, $49.5 \%$ $(n=5085)$ were HPV DNA positive and $50.5 \%$ $(n=5181)$ were negative. Figure (1) displays the overall HPV prevalence according to sex. HPV DNA was not detected in $44.0 \%(n=4510)$ of females and $6.5 \%$ $(n=671)$ of males while HPV was genotyped in $37.4 \%$ $(n=3841)$ of female subjects and $12.1 \%(n=1244)$ of male subjects.

Totally, among 5,085 samples from 31 Iranian provinces, four most common HPV genotypes were HPV-6, -11, -16, and -52 in male subjects and HPV-6, $-16,-11$, and $-52 /-53$ (HPV-52 and HPV-53 were equal in frequencies) in female subjects, in a descending order. Among HR and pHR HPV genotypes, after HPV-52/-53 (9.6\%), HR HPV-51 (8.0\%) had the highest frequency in female subjects and also other genotypes with prevalence less than $8 \%$ included pHR HPV-66 (7.7\%) and HR HPV-31 (7.0\%). In male subjects, HR HPV-51 (2.8\%) was the third most common HR HPV genotypes. The common HPV genotypes was observed in both single and mixed HPV infections and the genotypes which had high rates in the single HPV infection were also frequent in the mixed infections (Tables 1 and 2). Tehran accounted for the most HPV DNA positive patients (40.1\%) followed by Gilan (16.1\%) and Mazandaran (5.6\%) (Table 3).

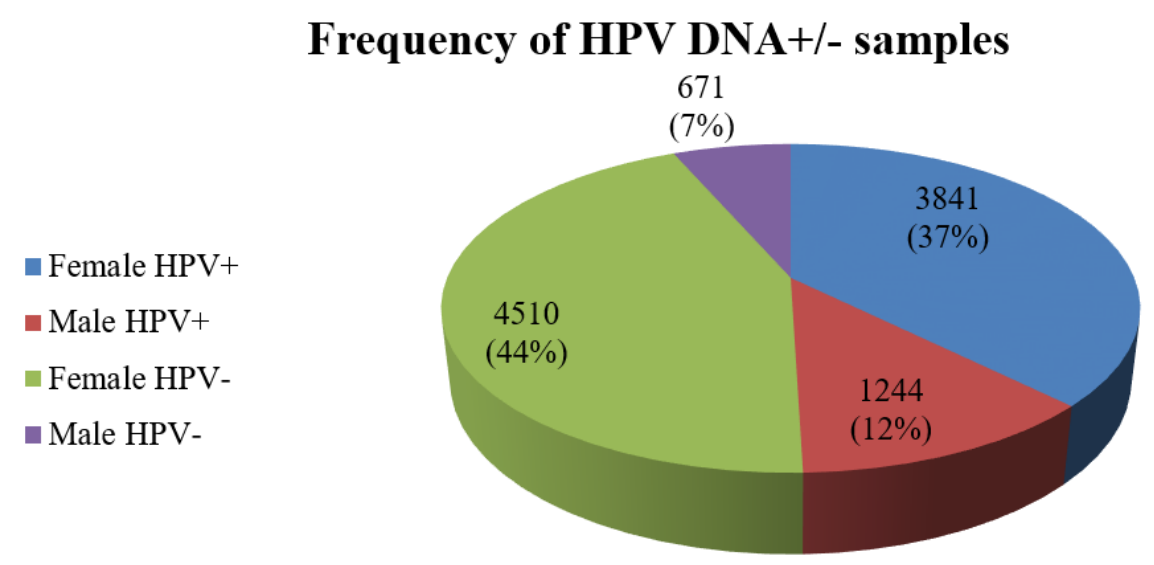


Figure 1. The percentage of HPV prevalence in the population $(n=10266)$ of this study. HPV DNA was not detected in $44.0 \%$ and $6.5 \%$ of females and males, respectively; however, $37.4 \%$ of female subjects and $12.1 \%$ of male subjects were positive for HPV DNA.

Table1. The prevalence of HPV genotypes as a single infection in Iranian female and male population

\begin{tabular}{|c|c|c|c|c|c|}
\hline & \multirow[b]{3}{*}{ HPV Genotypes } & \multicolumn{4}{|c|}{ Sex } \\
\hline & & \multicolumn{2}{|c|}{ Female } & \multicolumn{2}{|c|}{ Male } \\
\hline & & No & $\%, 95 \% \mathrm{CI}$ & No & $\%, 95 \% \mathrm{CI}$ \\
\hline \multirow{13}{*}{ LR HPV } & 6 & 1004 & $26.1(24.8-27.6)$ & 828 & $66.5(64.0-68.9)$ \\
\hline & 11 & 201 & $5.2(4.5-6.0)$ & 131 & $10.5(8.8-12.1)$ \\
\hline & 44 & 26 & $0.7(0.4-0.9)$ & 18 & $1.4(0.8-2.2)$ \\
\hline & 54 & 42 & $1.1(0.8-1.4)$ & 3 & $0.2(0.0-0.6)$ \\
\hline & 62 & 26 & $0.7(0.4-0.9)$ & 2 & $0.2(0.0-0.4)$ \\
\hline & 89 & 20 & $0.5(0.3-0.8)$ & 0 & $0(0.0-0.0)$ \\
\hline & 43 & 9 & $0.2(0.1-0.4)$ & 0 & $0(0.0-0.0)$ \\
\hline & 40 & 9 & $0.2(0.1-0.4)$ & 0 & $0(0.0-0.0)$ \\
\hline & 61 & 17 & $0.4(0.3-0.7)$ & 0 & $0(0.0-0.0)$ \\
\hline & 67 & 9 & $0.2(0.1-0.4)$ & 0 & $0(0.0-0.0)$ \\
\hline & 81 & 10 & $0.3(0.1-0.4)$ & 0 & $0(0.0-0.0)$ \\
\hline & 83 & 8 & $0.2(0.1-0.4)$ & 0 & $0(0.0-0.0)$ \\
\hline & 42 & 10 & $0.3(0.1-0.4)$ & 3 & $0.2(0.0-0.6)$ \\
\hline \multirow{6}{*}{ pHR HPV } & 53 & 108 & $2.8(2.3-3.4)$ & 3 & $0.2(0.0-0.6)$ \\
\hline & 66 & 65 & $1.7(1.3-2.1)$ & 6 & $0.5(0.2-0.9)$ \\
\hline & 26 & 10 & $0.3(0.1-0.4)$ & 0 & $0(0.0-0.0)$ \\
\hline & 73 & 12 & $0.3(0.2-0.5)$ & 1 & $0.1(0.0-0.2)$ \\
\hline & 82 & 12 & $0.3(0.1-0.5)$ & 1 & $0.1(0.0-0.2)$ \\
\hline & 70 & 6 & $0.2(0.1-0.3)$ & 1 & $0.1(0.0-0.2)$ \\
\hline \multirow{13}{*}{ HR HPV } & 16 & 214 & $5.6(4.8-6.2)$ & 34 & $2.7(1.8-3.6)$ \\
\hline & 18 & 35 & $0.9(0.7-1.2)$ & 3 & $0.2(0.0-0.6)$ \\
\hline & 31 & 23 & $0.6(0.4-0.8)$ & 2 & $0.2(0.0-0.4)$ \\
\hline & 35 & 19 & $0.5(0.3-0.7)$ & 1 & $0.1(0.0-0.2)$ \\
\hline & 39 & 45 & $1.2(0.8-1.5)$ & 3 & $0.2(0.0-0.6)$ \\
\hline & 45 & 24 & $0.6(0.4-0.9)$ & 1 & $0.1(0.0-0.2)$ \\
\hline & 51 & 72 & $1.9(1.5-2.3)$ & 11 & $0.9(0.4-1.4)$ \\
\hline & 52 & 86 & $2.2(1.8-2.7)$ & 8 & $0.6(0.2-1.1)$ \\
\hline & 56 & 33 & $0.9(0.6-1.2)$ & 4 & $0.4(0.1-0.7)$ \\
\hline & 58 & 28 & $0.7(0.5-1.0)$ & 1 & $0.1(0.0-0.3)$ \\
\hline & 68 & 21 & $0.5(0.3-0.8)$ & 1 & $0.1(0.0-0.2)$ \\
\hline & 59 & 10 & $0.3(0.1-0.4)$ & 3 & $0.2(0.0-0.6)$ \\
\hline & 33 & 7 & $0.2(0.1-0.3)$ & 1 & $0.1(0.0-0.3)$ \\
\hline \multirow[b]{2}{*}{ Total } & Mixed infection* & 1620 & $42.1(40.2-43.9)$ & 174 & $14.1(12.4-15.7)$ \\
\hline & & 3841 & 100.0 & 1244 & 100.0 \\
\hline
\end{tabular}

HR HPV= high risk HPV, $\mathrm{pHR}=$ possible high risk $\mathrm{HPV}, \mathrm{LR} \mathrm{HPV}=$ low risk $\mathrm{HPV}, \mathrm{F}=$ female, $\mathrm{M}=$ male 
The percentages were computed in the formula of 'the frequency/total number' (the total number was 3,841 in female subjects and 1,244 in male subjects).

*The data are shown in Table 2.

Table 2. The prevalence of HPV genotypes in mixed infections in Iranian female and male population

\begin{tabular}{ccccc}
\hline HPV genotypes & \multicolumn{2}{c}{ Females } & \multicolumn{2}{c}{ Males } \\
\hline $\begin{array}{c}\text { More frequent genotypes with other HPV } \\
\text { genotypes in mixed infections* }\end{array}$ & No & $\%, 95 \%$ CI & No & $\%, 95 \%$ CI \\
\hline HPV-6 & 659 & $40.7(38.2-43.0)$ & 139 & $79.9(73.6-85.6)$ \\
\hline HPV-11 & 236 & $14.6(13.0-16.5)$ & 40 & $23.0(16.7-29.3)$ \\
\hline HPV-16 & 426 & $26.3(24.3-28.6)$ & 34 & $19.5(13.8-25.9)$ \\
\hline HPV-52 & 282 & $17.4(15.6-19.2)$ & 32 & $18.4(12.7-24.1)$ \\
\hline HPV-53 & 259 & $16.0(14.2-17.8)$ & 15 & $8.6(4.6-13.2)$ \\
\hline HPV-31 & 247 & $15.2(13.5-17.1)$ & 13 & $7.5(4.0-12.1)$ \\
\hline HPV-51 & 236 & $14.6(13.0-16.5)$ & 24 & $13.8(9.2-19.0)$ \\
\hline HPV-66 & 232 & $14.3(12.7-16.1)$ & 16 & $9.2(5.2-13.8)$ \\
\hline HPV-39 & 178 & $11.0(9.4-12.5)$ & 9 & $5.2(2.3-8.6)$ \\
\hline HPV-45 & 143 & $8.8(7.3-10.3)$ & 11 & $6.3(2.9-10.3)$ \\
\hline Total number of mixed infections & 84 & $5.2(4.2-6.4)$ & 2 & $1.1(0.0-2.9)$ \\
\hline
\end{tabular}

The percentages were computed in the formula of 'the frequency/total number' (the total number was 3,841 in female subjects and 1,244 in male subjects).

*Other HPV genotypes obtained one or more of these HPV genotypes: HPV-16, -18, -31, -33, -35, -39, -45, -51, -52, $-56,-58,-59,-68,-26$, $-53,-66,-70,-73,-82,-6,-11,-40,-42,-43,-44,-54,-61,-62,-67,-81,-83$, and -89 .

Table 3. The frequency and percentage of HPV infections of 31 Iranian provinces among HPV DNA samples

\begin{tabular}{ccc}
\hline Province & Frequency & \%*, 95\% CI \\
\hline Alborz & 296 & $5.8(5.2-6.5)$ \\
\hline Ardabil & 80 & $1.6(1.2-1.9)$ \\
\hline Bushehr & 45 & $0.9(0.6-1.1)$ \\
\hline Chaharmahal and Bakhtiari & 31 & $0.6(0.4-0.8)$ \\
\hline East Azerbaijan & 68 & $1.3(1.0-1.7)$ \\
\hline Esfahan & 72 & $1.4(1.1-1.8)$ \\
\hline Fars & 67 & $1.3(1.0-1.7)$ \\
\hline Gilan & 817 & $16.1(15.0-17.1)$ \\
\hline Golestan & 23 & $0.5(0.3-0.6)$ \\
\hline Hamadan & 11 & $0.2(0.1-0.4)$ \\
\hline Hormozgan & 115 & $2.3(1.9-2.7)$ \\
\hline Ilam & 2 & $0.0(0.0-0.1)$ \\
\hline Kerman & 35 & $0.7(0.5-0.9)$ \\
\hline Kermanshah & 61 & $1.2(0.9-1.5)$ \\
\hline Khuzestan & 165 & $3.2(2.8-3.8)$ \\
\hline Korestan & 5 & $0.1(0.0-0.2)$ \\
\hline Kohgiluyeh and Boyer-Ahmad & 68 & $1.3(1.0-1.7)$ \\
\hline Kurdistan & $69-1.7)$ \\
\hline
\end{tabular}




\begin{tabular}{ccc}
\hline Markazi & 139 & $2.7(2.3-3.2)$ \\
\hline Mazandaran & 286 & $5.6(5.0-6.3)$ \\
\hline Northern Khorasan (Bojnord) & 62 & $1.2(0.9-1.5)$ \\
\hline Qazvin & 55 & $1.1(0.8-1.4)$ \\
\hline Qom & 203 & $4.0(3.5-4.6)$ \\
\hline Razavi Khorasan (Mashhad) & 43 & $0.8(0.6-1.1)$ \\
\hline Semnan & 25 & $0.5(0.3-0.7)$ \\
\hline Sistan and Baluchestan (Zabol) & 40 & $0.8(0.6-1.0)$ \\
\hline South Khorasan (Birjand) & 11 & $0.2(0.1-0.4)$ \\
\hline Tehran & 2073 & $40.8(39.4-42.1)$ \\
\hline West Azerbaijan & 58 & $1.1(0.9-1.5)$ \\
\hline Yazd & 48 & $0.9(0.7-1.2)$ \\
\hline Zanjan & 12 & $0.2(0.1-0.4)$ \\
\hline Total & 5085 & 100.0 \\
\hline
\end{tabular}

*The percentages were computed in the formula of 'the frequency/total number' (the total number was 5085).

Overall, the mixed HPV infections were found in $14.0 \%(\mathrm{n}=174)$ of HPV DNA positive males, while $42.2 \%(n=1620)$ of HPV infection in females were caused by mixed HPV genotypes. Concomitant infection with at least two LR HPV genotypes was detected in $3.3 \%(168 / 5085)$ of all positive cases. In both sexes with mixed HPV genotypes, concurrent infection by at least one HR and one LR HPV genotype was commonly observed than other forms of mixed infections (Table 2). Only $0.3 \%(n=11)$ of females had pHR HPV genotypes as the mixed infection, and no similar cases were not found in males (Table 4).

A total of 5,085 samples which were positive for HPV DNA were selected for more statistical analysis. They were divided into 4 age groups: 13-29, 30-44, 4559, and 60-74 years (Table 5). In our study, like other studies $(9,13)$ no statistically significant correlation was found between HPV infection and age $(P=1)$; however, $90.6 \%$ and $86.4 \%$ of the HPV infections in female and male subjects were seen in subjects aged 13 to 44 years, respectively. The highest rate of HPV infection occurred in positive subjects aged 30-44 years (Table 5). Figure (2) shows an upward trend of the frequency of HPV infection by age increasing with a peak at 30 and 32 years in both sexes. Along with age increasing, the rate of infection by HPV declines steadily and the lowest rate is seen in the age range 6074 years.

Distribution of HPV genotypes based on age groups was different in both sexes. In female subjects, HPV16, as the most HR HPV genotypes, was more observed in the age group 30-44 years. The second and third common HPV genotypes were HPV-53 and HPV-52, which were detected more frequently in the age group 30-44 years. Interestingly, these three genotypes were not found in female subjects older than 60 years old. HPV-6, as commonly detected LR HPV genotypes, was almost equal in two age groups (13-29 and 30-45 years). In male subjects, the subjects aged 30-44 years had the first and second most frequent HR HPV and LR HPV genotypes: HR HPV-16, -51/-52 (the frequencies of HPV-52 and HPV-53 were equal), and LR HPV-6, 11. In the participants $>60$ years of age, HPV -6 and 11 were the most detectable HPV genotypes (data not shown). Table 6 shows HPV prevalence and three common genotypes of noncancerous cervical samples in Iran's neighbouring countries. 


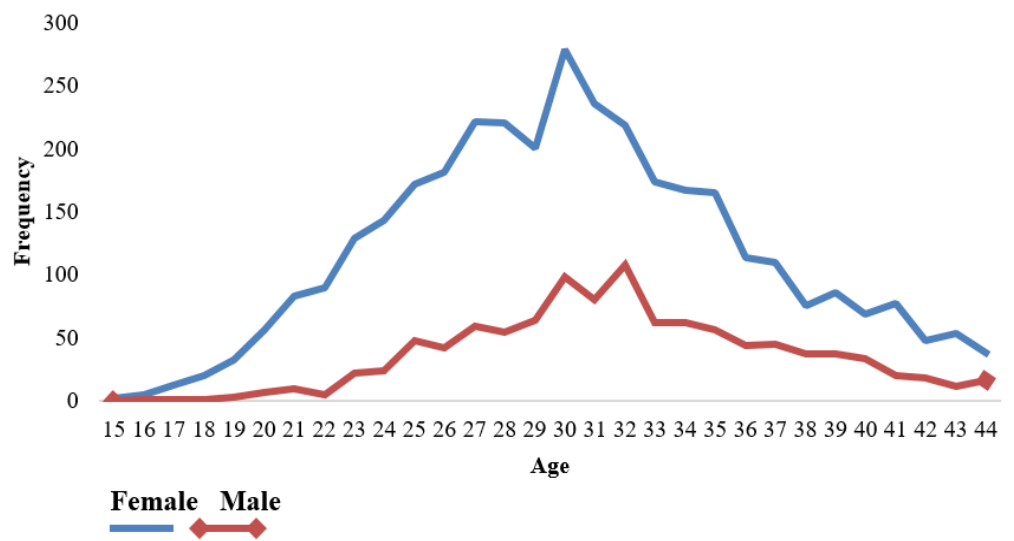

Figure2. The frequency of HPV infection according to the age in the studied males and females

Table 4. The prevalence of HPV genotypes in the mixed infections*

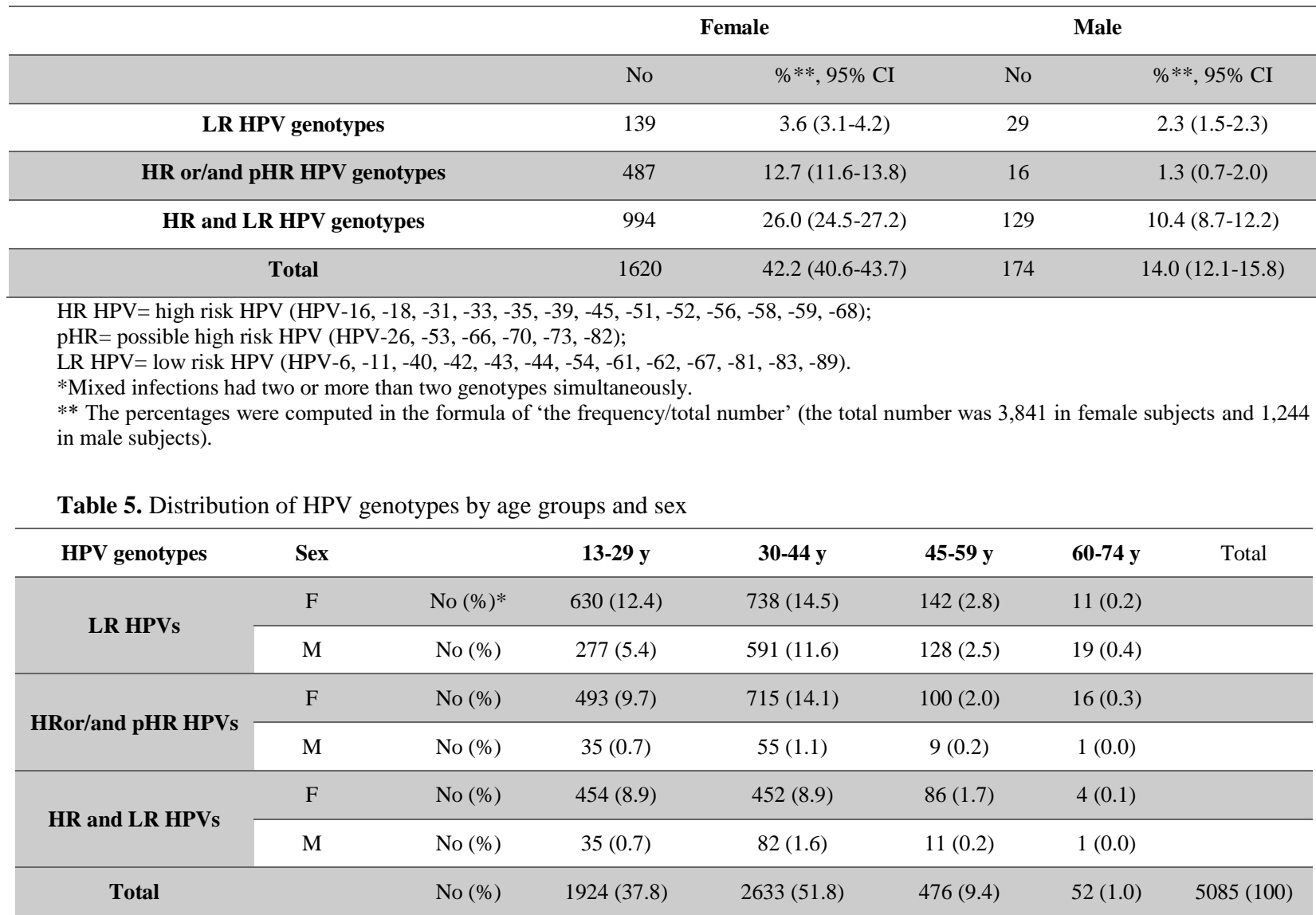

HR HPV= high risk HPV, pHR= possible high risk HPV, LR HPV= low risk HPV, F= female, M= male, No=number, y= year

* The percentages were computed in the formula of 'the subtotal frequency/total number' (the total number of all positive cases (5085).

Table 6. HPV prevalence and three common genotypes of noncancerous cervical samples in Iran's neighbouring countries*

\begin{tabular}{|c|c|c|c|c|}
\hline Country & $\begin{array}{c}\text { HPV prevalence in } \\
\text { healthy female subjects** } \\
\text { (Type of patients) }\end{array}$ & Three common genotypes & HPV genotyping assay & Reference \\
\hline \multirow{3}{*}{ Turkey } & \multirow{3}{*}{$\begin{array}{l}17.9 \% \\
\text { (patients with normal } \\
\text { pap smear) }\end{array}$} & HPV-16 (3.6\%), & \multirow{3}{*}{ line blot assay } & \multirow{3}{*}{ (30) } \\
\hline & & HPV-6 (2.6\%), & & \\
\hline & & HPV-45 (2.2\%) & & \\
\hline \multirow{3}{*}{$\begin{array}{l}\text { Pakistan } \\
\text { (Punjab) }\end{array}$} & \multirow{3}{*}{$\begin{array}{l}4.74 \% \\
\text { (patients with normal } \\
\text { cervical cytology) }\end{array}$} & HPV-6 (25\%), & \multirow{3}{*}{$\begin{array}{l}\text { the partial HPV L1 } \\
\text { region sequencing }\end{array}$} & \multirow{3}{*}{ (31) } \\
\hline & & HPV-55 (22.9\%), & & \\
\hline & & HPV-11 (20.8\%) & & \\
\hline
\end{tabular}




\begin{tabular}{|c|c|c|c|c|}
\hline \multirow{3}{*}{ Qatar } & \multirow{3}{*}{$\begin{array}{c}7.6 \% \\
\text { (patients with normal } \\
\text { and abnormal cervical } \\
\text { cytology) }\end{array}$} & HPV-81 (34.5\%), & \multirow{3}{*}{$\begin{array}{l}\text { real-time PCR and } \\
\text { Sanger sequencing }\end{array}$} & \multirow{3}{*}{ (32) } \\
\hline & & HPV-11 (31.0\%), & & \\
\hline & & HPV-35 (6.9\%) & & \\
\hline $\begin{array}{c}\text { Iraq } \\
\text { (Kurdistan Region) }\end{array}$ & $\begin{array}{l}12.5 \% \text { (Patients with } \\
\text { vaginal discharge) }\end{array}$ & HPV-16 (53.8\%) & Conventional PCR & (33) \\
\hline \multirow{3}{*}{ Kuwait } & \multirow{3}{*}{$\begin{array}{l}2.4 \% \\
\text { (patients with normal } \\
\text { cervical cytology) }\end{array}$} & HPV-11 (22.5\%), & \multirow{3}{*}{ PCR-based sequencing } & \multirow{3}{*}{ (34) } \\
\hline & & HPV-81 (18.3\%), & & \\
\hline & & HPV-61 (12.6\%), & & \\
\hline \multirow{4}{*}{$\begin{array}{c}\text { The Kingdom of } \\
\text { Bahrain }\end{array}$} & \multirow{4}{*}{$\begin{array}{l}9.8 \% \\
\text { (patients with normal } \\
\text { pap smear) }\end{array}$} & HPV-52 (1.4\%), & \multirow{4}{*}{$\begin{array}{l}\text { PCR DNA enzyme } \\
\text { immunoassay (PCR- } \\
\text { DEIA) and LiPA25 } \\
\text { system }\end{array}$} & \multirow{4}{*}{$(35)$} \\
\hline & & HPV-16 (1.1\%) & & \\
\hline & & HPV-31 (1.1\%) & & \\
\hline & & HPV-51 (1.1\%) & & \\
\hline
\end{tabular}

\section{Discussion}

HPV distribution varies in different countries and populations and even though in various parts of a country. For example, HPV-16 in Zhejiang province, HPV-52 in Guiyang and Guangdong provinces, and HPV-6 in Xi'an province of China are predominant genotypes $(14,15)$. In this study, we examined 10,266 Iranian male and female subjects with normal papsmear, cell collections from vagina, cervix, and bulge of penile and anal sites of males from 31 provinces which showed an overall HPV prevalence of $49.5 \%$. Based on a global study on female subjects with normal pap-smear, this rate of HPV prevalence was much higher than both neighboring countries and other regions in the world. The highest burden of HPV infection was estimated in African and Latin American countries and the lowest in southern Europe and South East Asia (12). No fixed pattern of the HPV genotypes distribution observed even in different parts of a province, e,g, the samples from suburb of Tehran commonly demonstrated mixed infections (the data were not shown). Although no sociodemographic data are available, low education and inappropriate economic conditions may be an explanation, high risk HPV distribution is affected by sexual behavior, host immune factors, environmental factors, smoking, having multiple sex partners, and the presence of other sexually transmitted infections (16). Therefore, HPV as an important transmitted infection causes some critical HPV-associated cancers in human, circulating HPV genotypes should be available to plan better the prevention. In different studies done on routine papsmear samples in Iran, HPV-16 and -18 represented as the main genotypes $(13,17,18)$, which are in disagreement with our results, as HPV-18 contained $9^{\text {th }}$ or higher in our study. Vaccinated female may reduce the HPV infections in male subjects, due to herd immunity (19); hence, domination of HPV-6, -11, -16, and -52 in female subjects of this study may explain the prevalence of these HPV genotypes in male subjects or vice versa. Table (6) displays the overall HPV genotypes prevalence and three frequent HPV genotypes in female subjects of Iran's neighboring countries. Not only no common distribution pattern was observed between Iran and its neighbors, but also our findings are in contradiction with previous surveys conducted in Iran. In addition, in Saudi Arabia, as a country which Iranian people travel annually for pilgrimage, HPV-16, -18, and -11 were reported as three common genotypes (20). According to the latest report, cervical cancer is the $12^{\text {th }}$ most common cancer among Iranian female (7). On the one hand, based on our findings, the major genotype circulating in the normal population is HPV-6, which may justify the reduction of cervix cancer in the country. On the other hand, HPV-16 as the most important HR HPV genotype in the studied population and cancerous samples (3) has generally four lineages (A-D) that nonEuropean variants (B-D) (21) play a key role in the development of an invasive form of cervical cancer (22). D is the prevalent lineage in Iranian females (23). Therefore, the importance of vaccination is well perceptible. In addition, there are no regular cervical cancer screening, either vaccination program or a national cancer registry. This study, in line with other previous studies, recommends to set up serious hygiene policies in case of HPV infections.

Men with HPV infection only accounted for $12.1 \%$ of all HPV DNA cases. Among this, $86.0 \%$ had a single infection. The predominant three HPV genotypes found were in complete agreement with those were reported by Salehi-Vaziri in 2015 (9). Only almost oneseventh of male subjects were positive for mixed infections compared to the female subjectss where less than half of them were infected with mixed HPV genotypes. In Iran, nearly all boys are circumcised before the age of seven because of religious beliefs. Based on two meta-analysis studies, although no association was observed between HPV clearance and HPV acquisition of new infections, there was a significant reduction in genital HPV infection prevalence in male circumcision $(\mathrm{OR}=0.57)(24,25)$, which may be a possible reason in the reduction of HPV infections or mixed infections in male subjects of this study. 
The age distribution of HPV infection in both sexes showed a mono summit graph with a peak age of 3032 years. There was the highest incidence in the age of marriage and after beginning of the sexual activity due to some cultural habits, religious beliefs such as not to have illegitimate sex, increasing the age of marriage, and absence of immune protection against HPV in the lack of national vaccination program. Also, the rate of mixed infections is increased with the rise in the frequency of sexual contact and high-risk sexual behaviour (26). The steady decrease in the HPV infection rate in the middle age and elder individuals might explain the present immunity due to the natural history of HPV infection or self-limiting HPV infection within 18 months after infection as a result of host immune responses $(15,27)$. Although we had no information about the sexual activity of the participants or the status of HPV infection in parents of the children, self- or hetero-inoculation, the route of spreading of LR HPV infections in young people who have no sexual experiences, may justify the presence of HPV genotypes in the adolescents. $(28,29)$.

An important limitation of this study was the lack of cytology information of positive samples for correlation with the results of HPV genotypes. Another limitation, this rate of HPV prevalence may not reflect the distribution of HPV genotypes in the country since this study recruited only the samples with normal papsmear, cell collections from vagina, and cervix in female subjects, and bulge of penile and anal sites in male subjects. Hence, similar studies need to be conducted on cancerous samples. No demographic data of participants such as marital status, job, and the number of sex partners were available. In spite of the male subjects' limitations, this study gives an insight into the present status of the distribution of HPV genotypes in the target population and is helpful for setting policies.

\section{Acknowledgements}

The authors wish to thank the staff of Keyvan Laboratory for their assistance and unaccountable technical supports in this study. H. K designed the study and provided technical help and material support. M. M K performed the study and analysed the statistical subjects.

\section{Conflict of Interest}

The authors declare that there is no conflict of interest regarding the publication of this article.

\section{References}

1. Gao G, Smith DI. Human Papillomavirus and the Development of Different Cancers. Cytogenet Genome Res. 2016;150(3-4):185-93. [DOI:10.1159/000458166] [PMID]

2. Bouvard V, Baan R, Straif K, Grosse Y, Secretan B, El Ghissassi F, et al. A review of human carcinogens--Part B: biological agents. Lancet Oncol. 2009;10(4):321-2. [DOI:10.1016/S1470-2045(09)70096-8]

3. Jalilvand S, Shoja Z, Nourijelyani K, Tohidi HR, Hamkar R. Meta-analysis of type-specific human papillomavirus prevalence in Iranianfemale subjects with normal cytology, precancerous cervical lesions and invasive cervical cancer: Implications for screening and vaccination. Journal of medical virology. 2015;87(2):287-95. [DOI:10.1002/jmv.24053] [PMID]

4. Malary M, Moosazadeh M, Hamzehgardeshi Z, Afshari M, Moghaddasifar I, Afsharimoghaddam A. The prevalence of cervical human papillomavirus infection and the most at-risk genotypes among Iranian healthyfemale subjects: A systematic review and meta-analysis. International journal of preventive medicine. 2016;7. [DOI:10.4103/20087802.181756] [PMID] [PMCID]

5. Torre LA, Bray F, Siegel RL, Ferlay J, Lortet-Tieulent J, Jemal A. Global cancer statistics, 2012. CA Cancer J Clin. 2015;65(2):87-108. [DOI:10.3322/caac.21262] [PMID]

6. Guan P, Howell-Jones R, Li N, Bruni L, de Sanjose S, Franceschi S, et al. Human papillomavirus types in 115,789 HPV-positivefemale subjects: a meta-analysis from cervical infection to cancer. Int J Cancer. 2012;131(10):2349-59. [DOI:10.1002/ijc.27485] [PMID]

7. Bruni L B-RL, Albero G, Serrano B,male subjectsa M, Gómez D, Muñoz J, Bosch FX, de Sanjosé, Centre). SIICoHaCHI. Human Papillomavirus and Related Diseases in Iran.

8. Sudenga SL, Torres BN, Silva R, Villa LL, Lazcano-Ponce E, Abrahamsen M, et al. Comparison of the Natural History of Genital HPV Infection amongmale subjects by Country: Brazil, Mexico, and the United States. Cancer Epidemiol Biomarkers Prev. 2017;26(7):1043-52. [DOI:10.1158/10559965.EPI-17-0040] [PMID] [PMCID]

9. Salehi-Vaziri M, Sadeghi F, Bokharaei-Salim F, Younesi S, Alinaghi S, Monavari SH, et al. The Prevalence and Genotype Distribution of Human Papillomavirus in the Genital Tract of Males in Iran. Jundishapur J Microbiol. 2015;8(12):e21912. [DOI:10.5812/jjm.21912]

10. Khorasanizadeh F, Hassanloo J, Khaksar N, Mohammad Taheri S, Marzaban M, B HR, et al. Epidemiology of cervical cancer and human papilloma virus infection among Iranianfemale subjects - analyses of national data and systematic review of the literature. Gynecol Oncol. 2013;128(2):277-81. [DOI:10.1016/j.ygyno.2012.11.032] [PMID]

11. Sharma D, Priyadarshini P, Vrati S. Unraveling the web of viroinformatics: Computational tools and databases in virus research. Journal of Virology. 2015;89(3):1489-501. [DOI:10.1128/JVI.02027-14] [PMID] [PMCID]

12. Biological agents. Volume 100 B. A review of human carcinogens. IARC Monogr Eval Carcinog Risks Hum. 2012;100(Pt B):1-441.

13. Khodakarami N, Clifford GM, Yavari P, Farzaneh F, Salehpour S, Broutet N, et al. Human papillomavirus infection infemale subjects with and without cervical cancer in Tehran, Iran. Int J Cancer. 2012;131(2):E156-61. [DOI:10.1002/ijc.26488] [PMID]

14. Liu XX, Fan XL, Yu YP, Ji L, Yan J, Sun AH. Human papillomavirus prevalence and type-distribution amongfemale subjects in Zhejiang Province, Southeast China: a cross-sectional study. BMC Infect Dis. 2014;14:708. [DOI:10.1186/s12879-014-0708-8] [PMID] [PMCID]

15. Wang R, Guo XL, Wisman GB, Schuuring E, Wang WF, Zeng ZY, et al. Nationwide prevalence of human papillomavirus infection and viral genotype distribution in 
37 cities in China. BMC Infect Dis. 2015;15:257. [DOI:10.1186/s12879-015-0998-5] [PMID] [PMCID]

16. Roik E, Sharashova E, Kharkova O, Nieboer E, Postoev V, Odland JO. Sociodemographic characteristics, sexual behaviour and knowledge about cervical cancer prevention as risk factors for high-risk human papillomavirus infection in Arkhangelsk, North-West Russia. Int J Circumpolar Health. 2018;77(1):1498681. [DOI:10.1080/22423982.2018.1498681] [PMID] [PMCID]

17. Ghaffari SR, Sabokbar T, Mollahajian H, Dastan J, Ramezanzadeh F, Ensani F, et al. Prevalence of human papillomavirus genotypes infemale subjects with normal and abnormal cervical cytology in Iran. Asian Pac J Cancer Prev. 2006;7(4):529-32.

18. Shafaghi B, Jarollahi A, Yousefzadeh B, Ameri A, Moghadam S, Mostafavi M. Human papilloma virus prevalence and types among Iranianfemale subjects attending regular gynecological visits. Reports of Radiotherapy and Oncology. 2013;1(2).

19. Malagon T, Laurie C, Franco EL. Human papillomavirus vaccination and the role of herd effects in future cancer control planning: A review. Expert Rev Vaccines. 2018. [DOI:10.1080/14760584.2018.1471986] [PMID]

20. Al-Ahdal MN, Al-Arnous WK, Bohol MF, Abuzaid SM, Shoukri MM, Elrady KS, et al. Human papillomaviruses in cervical specimens offemale subjects residing in Riyadh, Saudi Arabia: a hospital-based study. J Infect Dev Ctries. 2014;8(3):320-5. [DOI:10.3855/jidc.4220] [PMID]

21. Burk RD, Harari A, Chen Z. Human papillomavirus genome variants. Virology. 2013;445(0):232-43. [DOI:10.1016/j.virol.2013.07.018] [PMID] [PMCID]

22. Shang Q, Wang Y, Fang Y, Wei L, Chen S, Sun Y, et al. Human Papillomavirus Type 16 Variant Analysis of E6, E7, and L1 Genes and Long Control Region in Identification of Cervical Carcinomas in Patients in Northeast China. Journal of Clinical Microbiology. 2011;49(7):2656-63. [DOI:10.1128/JCM.02203-10] [PMID] [PMCID]

23. Vaezi T, Shoja Z, Hamkar R, Shahmahmoodi S, Nozarian Z, Marashi SM, et al. Human papillomavirus type 16 lineage analysis based on E6 region in cervical samples of Iranianfemale subjects. Infect Genet Evol. 2017;55:26-30. [DOI:10.1016/j.meegid.2017.08.025] [PMID]

24. Albero G, Castellsague X, Giuliano AR, Bosch FX. Male circumcision and genital human papillomavirus: a systematic review and meta-analysis. Sex Transm Dis. 2012;39(2):10413. [DOI:10.1097/OLQ.0b013e3182387abd] [PMID]

25. Zhu YP, Jia ZW, Dai B, Ye DW, Kong YY, Chang K, et al. Relationship between circumcision and human papillomavirus infection: a systematic review and metaanalysis. Asian J Androl. 2017;19(1):125-31.
26. Lenselink CH, Melchers WJ, Quint WG, Hoebers AM, Hendriks JC, Massuger LF, et al. Sexual behaviour and HPV infections in 18 to 29 year oldfemale subjects in the prevaccine era in the Netherlands. PLoS One. 2008;3(11):e3743. [DOI:10.1371/journal.pone.0003743] [PMID] [PMCID]

27. Doorbar J. Host control of human papillomavirus infection and disease. Best Pract Res Clin Obstet Gynaecol. 2017. [DOI:10.1016/j.bpobgyn.2017.08.001] [PMID]

28. Ryndock EJ, Meyers C. A risk for non-sexual transmission of human papillomavirus? Expert Rev Anti Infect Ther. 2014;12(10):1165-70. [DOI:10.1586/14787210.2014.959497] [PMID]

29. Sabeena S, Bhat P, Kamath V, Arunkumar G. Possible nonsexual modes of transmission of human papilloma virus. J Obstet Gynaecol Res. 2017;43(3):429-35. [DOI:10.1111/jog.13248] [PMID]

30. Demir ET, Ceyhan M, Simsek M, Gunduz T, Arlier S, Aytac $\mathrm{R}$, et al. The prevalence of different HPV types in Turkishfemale subjects with a normal Pap smear. J Med Virol. 2012;84(8):1242-7. [DOI:10.1002/jmv.23333] [PMID]

31. Aziz H, Iqbal H, Mahmood H, Fatima S, Faheem M, Sattar AA, et al. Human papillomavirus infection in females with normal cervical cytology: Genotyping and phylogenetic analysis amongfemale subjects in Punjab, Pakistan. International Journal of Infectious Diseases. 2018;66:83-9. [DOI:10.1016/j.ijid.2017.11.009] [PMID]

32. Elmi AA, Bansal D, Acharya A, Skariah S, Dargham SR, Abu-Raddad LJ, et al. Human Papillomavirus (HPV) Infection: Molecular Epidemiology, Genotyping, Seroprevalence and Associated Risk Factors among Arabfemale subjects in Qatar. PLoS One. 2017;12(1):e0169197.

[DOI:10.1371/journal.pone.0169197] [PMID] [PMCID]

33. Hussein NR, Balatay AA, Assafi MS, AlMufty TA. High Risk Human Papilloma Virus Genotypes in Kurdistan Region in Patients with Vaginal Discharge. Asian Pac J Cancer Prev. 2016;17(7):3191-3.

34. Al-Awadhi R, Chehadeh W, Kapila K. Prevalence of human papillomavirus amongfemale subjects with normal cervical cytology in Kuwait. J Med Virol. 2011;83(3):453-60. [DOI:10.1002/jmv.21981] [PMID]

35. Moosa K, Alsayyad AS, Quint W, Gopala K, DeAntonio R. An epidemiological study assessing the prevalence of human papillomavirus types infemale subjects in the Kingdom of Bahrain. BMC Cancer. 2014;14:905. [DOI:10.1186/14712407-14-905] [PMID] [PMCID] 